\title{
Developing an integrated curriculum for patient safety in an undergraduate nursing program: a case study
}

Yoonjung Ji ${ }^{1}$, Hyeonkyeong Lee ${ }^{1 *}$, Taewha Lee ${ }^{1}$, Mona Choi ${ }^{1}$, Hyejung Lee ${ }^{1}$, Sanghee Kim ${ }^{1}$, Hyunok Kim Do ${ }^{1,2}$, Sunah Kim', Sang Hui Chu', Jeongok Park', Young Man Kim³ and Soyoon Park'

\begin{abstract}
Background: Nursing students' practical training should begin when students can apply core knowledge, skills, and attitudes related to patient safety. This necessitates an integrated curriculum in nursing education that links practice to the theory concerning patient safety to enhance patient safety competencies and quality in nursing care. This study aimed to develop an integrated curriculum that incorporates patient safety factors in the existing curriculum to increase patient safety competencies in nursing students.

Method: A case study approach was adopted to explain the development processes of a new curriculum integrating patient safety in the existing outcome-based curriculum of a nursing college. Based on the existing outcome-based curriculum of a nursing college, a four-step process was performed to integrate patient safety component, including quality improvement, into the curriculum: 1) literature review, 2) analysis of course syllabus, 3) selection of courses related to patient safety topics, and 4) development of evaluation tool.

Results: The integrated patient safety curriculum was based on six topics: patient safety principles, teamwork, communication, patient engagement, risk management and, quality improvement, and International Patient Safety Goals. Based on the characteristics of the course according to the level of students in each year, the curriculum was integrated to address patient safety topics in seven courses (four theoretical and three practical). A Patient safety Competency self-assessment checklist was developed for students to naturally acquire patient safety competencies in clinical settings.
\end{abstract}

Conclusions: This study demonstrated that patient safety topics should be addressed in both theoretical and practical settings across the entire nursing curriculum per the continuity and sequence of education principles.

Keywords: Patient safety, Nursing education, Curriculum, Nursing student, Competency

\section{Background}

Improving the quality of healthcare systems has been gaining increased attention since the 2000s, necessitating new paradigms for quality improvement [1]. A report by the Institute of Medicine revealed that, in 2000, the

\footnotetext{
* Correspondence: HLEE39@yuhs.ac

1 Mo-Im Kim Nursing Research Institute, College of Nursing, Yonsei University, Seoul, Republic of Korea

Full list of author information is available at the end of the article
}

number of deaths resulting from medical accidents was greater than the total number of deaths from motor vehicle accidents and HIV, leading to immense health care costs [2]. Therefore, patient safety is gaining priority in health care settings to avoid unnecessary harm to patients [3]. Patient safety involves minimizing risks and reducing exposure to mistakes and near misses during delivering health care services [2]. Over the past 10 years, efforts have been made in policy, research, and

(c) The Author(s). 2021 Open Access This article is licensed under a Creative Commons Attribution 4.0 International License, which permits use, sharing, adaptation, distribution and reproduction in any medium or format, as long as you give appropriate credit to the original author(s) and the source, provide a link to the Creative Commons licence, and indicate if changes were made. The images or other third party material in this article are included in the article's Creative Commons licence, unless indicated otherwise in a credit line to the material. If material is not included in the article's Creative Commons licence and your intended use is not permitted by statutory regulation or exceeds the permitted use, you will need to obtain permission directly from the copyright holder. To view a copy of this licence, visit http://creativecommons.org/licenses/by/4.0/ The Creative Commons Public Domain Dedication waiver (http://creativecommons.org/publicdomain/zero/1.0/) applies to the data made available in this article, unless otherwise stated in a credit line to the data. 
service to improve patient safety and reduce medical errors [4]. In the general industry, safety management focuses on preventing institutional financial losses [5]. Contrastingly, patient safety management in health care settings entails financial problems and the negative consequences that may occur to patients [6]; errors must not further progress into harm [7]. Therefore, health care professionals play an important role in patient safety in today's health care environments, where improvement of patient safety and quality of care is the main outcome. For example, in Korea, the Ministry of Health and Welfare in 2018 announced the improvement of patient safety education for prospective health care professionals as part of their comprehensive patient safety plan [8]. Therefore, the increasing interest in ensuring nursing students' competency in enhancing patient safety has been reflected in the curriculum [7]

In the 2000s, nursing education has faced numerous obstacles, which delayed education on patient safety [9]. These include a lack of awareness that patient safety training may increase patient safety skills [10], lack of confidence in preparation of curriculum and teaching methods for patient safety in nursing faculty [11], and traditional health care environments that emphasize treatment rather than disease prevention. In the U.S., the Quality and Safety Education for Nurses (QSEN) project, which started in 2005, was the first to include patient safety as an essential competency in nursing education [12]. Furthermore, in 2011, the World Health Organization (WHO) presented the guidelines on patient safety curriculum for prospective health professionals to increase their patient safety competency [13]. Since then, six competencies of QSEN-patient-centered care, teamwork and collaboration, use of the evidencebased practice, quality improvement skills, integrated use of informatics, and patient safety-have been integrated into the planning and certification standards for curriculums of nursing schools. Further, QSEN has been providing resources to increase competency in nursing academia [14]. In Canada, the Canadian Association of Schools of Nursing (CASN) and the Canadian Patient Safety Institute announced the CASN National Education Framework to provide directions and principles on interprofessional patient safety competencies for nursing students [15]. However, patient safety education is not included as a recommended or essential part of the nursing curriculum in nursing schools in Korea.

As nursing students are first exposed to clinical settings in their clinical placement, a curriculum for systemic and continuous learning of knowledge, skills, and attitudes required for patient safety must be developed before and after their clinical training. Nursing students are recommended to begin their clinical training after acquiring core knowledge, skills, and attitudes related to patient safety through theoretical classes to cope with criticism on safety incidents [16]. Therefore, content and outcomes that link theory and practice are fundamental for designing curriculums on patient safety. Previous studies on topics such as integrating quality and safety education into clinical nursing practice [17] and developing patient safety courses through literature reviews have been reported [18]; however, studies on nursing curricula are rare [19]. Additionally, patient safety education is new, contains multidisciplinary topics, such as human factors, systemic thinking, effective teamwork, and error management, which were not included in the previous program, and is contextually related to the educational content of the existing curriculum. Therefore, contextualizing the principles of patient safety across the entire curriculum is important. Thus, it is recommended that effective patient safety-related educational content is integrated into the existing curriculum rather than creating a new stand-alone course on patient safety [13]. Therefore, this study was performed to develop an integrated curriculum that assimilates patient safety elements in the existing curriculum to increase patient safety competencies in nursing students.

\section{Methods}

This is a case study explaining the development processes of a new curriculum integrating patient safety into the existing outcome-based curriculum of a nursing college. Patient safety was newly added to core competencies in the curriculum revision stage for nursing students to respond to the needs of healthcare environment change. Accordingly, an approach that can be integrated into the current curriculum was attempted to achieve patient safety learning outcomes at the time of graduation.

The curriculum is 4 years long in the nursing college, and 126 theoretical credit hours $(90$ required credit hours for the major program) and $1116 \mathrm{~h}$ of clinical practice are mandatory. The first and second year of the curriculum include basic major courses and elective courses, simulation for clinical practice, and courses on the practice of core skills. In the third and fourth year of the curriculum, major courses are offered as an integrated curriculum based on Gordon's functional health patterns [20]. The integrated curriculum is divided into eight domains: nutrition-metabolism-elimination, activity-rest, cognition-perception, self-concept-value/ belief, roles/relationships-stress/coping, and sexuality. Each domain is integrated into courses on the nursing theory I-V and integrated nursing practice I-IV.

Based on the current curriculum, a four-step process to integrate patient safety factors, as well as quality improvement, were performed in the curriculum: 1) literature review, 2) analysis of course syllabuses, 3) selection 
of courses related to patient safety topics, and 4) development of evaluation tool (Fig. 1).

\section{Literature review}

The literature on patient safety competency for nursing students presented by international professional organizations was searched to select patient safety and quality improvement topics. The CASN National Education Framework [15], the WHO Patient Safety Curriculum Guide [13], and International Patient Safety Goals (IPSG) by JCI were included in the analysis [21].

\section{Analysis of course syllabus}

The syllabus of the existing curriculum was analyzed to assess how patient safety factors were reflected in the existing curriculum and the courses in which they needed to be reflected. The learning outcomes and core topics of the syllabuses of 29 courses (24 required major courses on theory, four required major courses on practical training, and one elective major course) from all the courses offered from the first to the fourth year of the program were analyzed. First, courses related to patient safety and quality improvement were listed. Second, curriculum committee meetings were held, and experts were consulted for advice. Finally, an agreement on the curriculum improvements was reached through workshops with professors.

\section{Selection of courses related to patient safety topics}

The courses identified by analyzing the syllabuses were classified as theoretical and practical courses, and the patient safety topics were selected, considering the students' level each year. Experts were consulted to set the range and topics of patient safety related to the selected topics in each course. At the faculty workshops, the linkage of one of the program outcomes of the curriculum-"improvement of patient safety and quality" - and two performance criteria-"students can explain the principles of patient safety and quality improvement." Furthermore, "students can perform nursing practice according to guidelines and procedures for improving patient safety, and quality"-with the identified theoretical and practical courses were reviewed. Further, discussions were held regarding its effectiveness in developing competency in patient safety and quality among the students.

\section{Development of evaluation tool}

A patient safety competency checklist (PSC Checklist) was developed to enable students to enumerate the essential patient safety principles applicable in clinical practicum and self-evaluate their performance. A literature review was performed, and patient safety experts were consulted. Additionally, the PSC Checklist was reviewed by education experts, including clinical instructors and faculty members, and underwent language editing. A content validity test was also conducted by 16 teaching assistants with more than 2 years of clinical experience as a clinical instructor. Each item was assessed on a four-point Likert scale where 4 and 1 points denoted "highly valid" and "not valid at all," respectively. If the item was rated as valid, it was classified into three types of practice level: observation, performance, and discussion. Moreover, two faculty workshops were held to prepare the final version of the checklist by reviewing the validity of the checklist items and discussing the appropriate implementation method. Lastly, the final version of the PSC Checklist was reviewed by an expert in Korean with previous experience in language editing to convey the intended meaning to the students accurately.

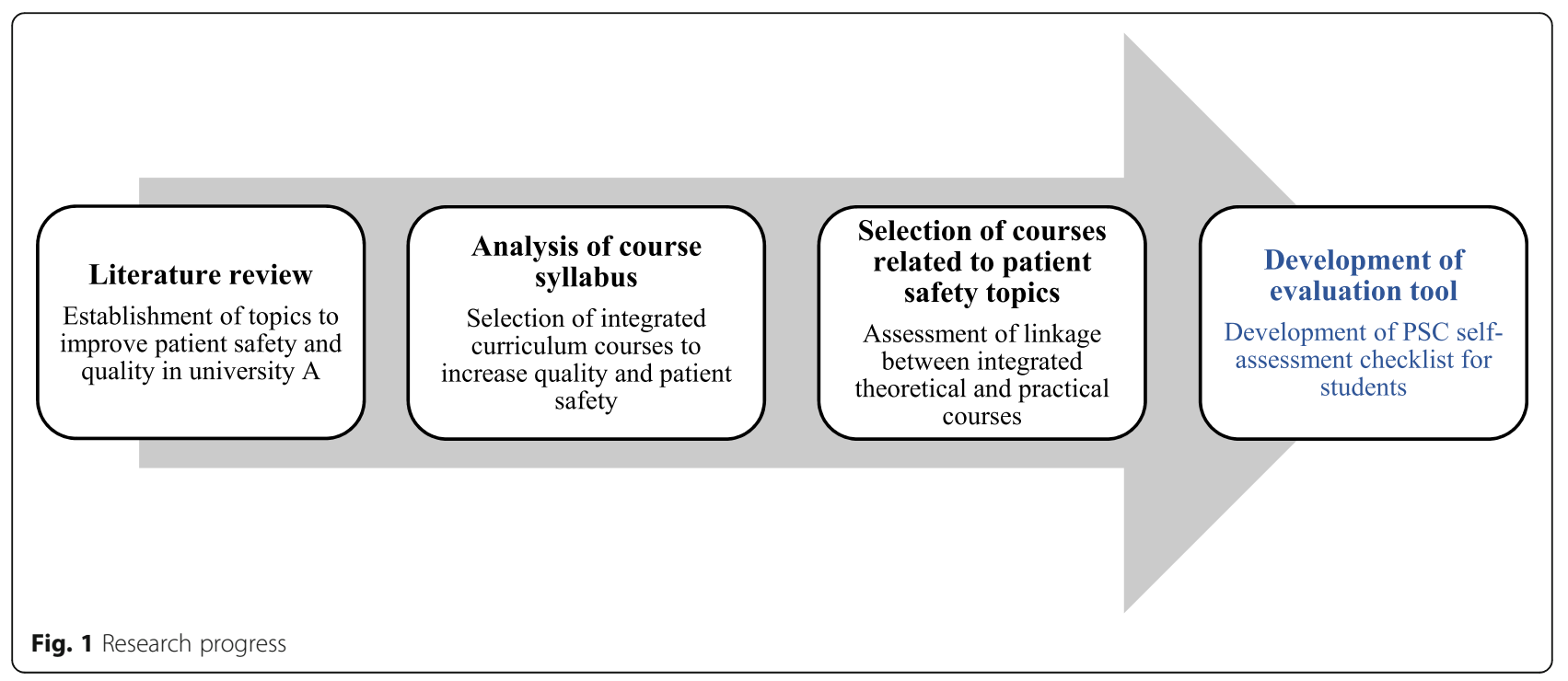




\section{Results}

\section{Establishment of patient safety topics}

The analysis revealed six topics on patient safety based on the six patient safety competency domains proposed by CASN, 11 educational topics suggested by the WHO, and IPSG by JCI (Fig. 2). For example, WHO's "what is patient safety" and CASN's "contribute to a culture of patient safety" were derived as "concept of patient safety," one of the sub-topics of patient safety principles, the patient safety topic of this university. By integrating WHO's "Why applying human factors is important for patient safety?" and CASN's "Optimize human and environmental factors," the topics were derived as "Human factor" and "Systems" among the sub-topics of patient safety principles. Consequently, first, the sub-topics of patient safety principles consist of concepts, human factors, and systems. Contents on basic concepts were included in addition to human factors and systems that affect patient safety to improve the understanding of students who are new to patient safety. Second, information on organizing and working as a team for patient safety through teamwork and how to form multi-disciplinary cooperation works were included. Third, information on the definition of communication for patient safety and ways to communicate were included. Fourth, engaging patients and families in the treatment process were presented as a strategy to prevent accidents. Fifth, the overall process of identifying factors that harm patient safety and strategies to improve and resolve it were included for risk management and quality improvement. Lastly, the IPSG from JCI was also included. In the case of this university, a clinical practice course is provided from the third year (for 1 year) at a JCI-certified medical institution. Thus, IPSG, which can be repeatedly learned in various settings according to the curriculum's principle of continuity and integration, has been added as the educational content. Safety guidelines related to infection, invasive behavior, and drugs, which can directly affect patient safety, were included to develop coping skills for handling various situations that may occur in clinical practice. Through the above process, patient safety topics presented by credible organizations such as WHO, CASN, and JCI were integrated into the university's patient safety topics.

\section{Selection of integrated curriculum courses for patient safety competency}

Based on the course characteristics according to the students' level each year, which were obtained by analyzing existing syllabuses, the curriculum was revised to address patient safety topics in a total of seven courses. This included four theoretical (one for each grade) and

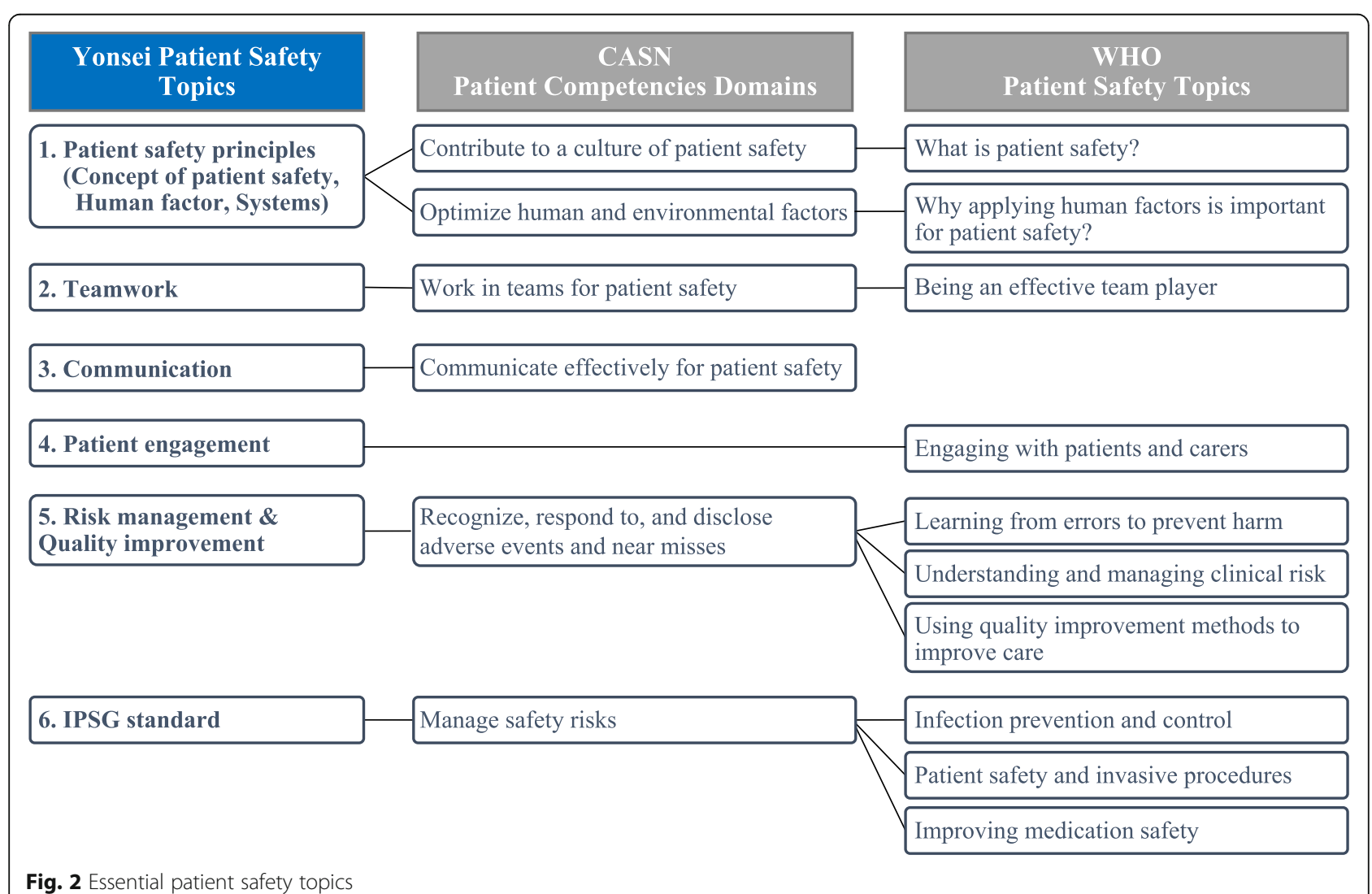

Fig. 2 Essential patient safety topics 
three practical (one for the third year and two for the fourth year). In theoretical courses, the basic concepts of patient safety and patient engagement were introduced for approximately 3 hours in Understanding of Nursing, the first major course in the program's first year. Understanding that patient safety is the most basic nursing concept positively affects students' performance concerning patient safety. Moreover, the most important aspect of patient safety is patient engagement must be acknowledged from the start of the curriculum. The assignment of patient safety topics within these courses was considered regarding the level of students with a relatively low understanding of the major. Wherein allowing them to naturally acquire knowledge of the course by encountering the most basic patient safety subject from the moment they entered the nursing college.

Of the second-year courses, there was Introduction to Clinical Nursing Practice fosters knowledge and skills in basic nursing techniques before clinical training. It was modified to offer a one-hour training on the rationale and methods for considering human factors in patient safety accidents and another one-hour training on IPSG, which together form the core of basic nursing. Among the third-year courses, Communication II, an intensive communication course, was revised to offer a two-hour lecture module on communication in a team to ensure patient safety. The consensus among nursing faculty was carried out through several faculty meetings to establish a linkage between patient safety topics and courses. For example, teamwork, mainly taught in the Nursing Management course, was added to the Communication II course because communication is the most important capability in teamwork for patient safety. Moreover, the Nursing Management course in the fourth year was revised to include a six-hour module on risk management and quality improvement. Thus, the curriculum was reorganized to include elements of patient safety and the overall contents of the existing courses.

Among the practical courses, Integrated Nursing Practice I and II, which are third-year practical courses, were modified to include a 1.5 -h special lecture on patient safety principles, patient engagement, and IPSG standards before clinical training. This course was modified to help students understand why patient safety is systemically important in hospitals, why patient engagement is important for patient safety, and the basic safety rules, essential for patient safety. The special lecture is provided to third-year students who are new to clinical practicum before they experience the field to remind them about patient safety topics to enhance the integration of theory-practice and safety accident prevention and coping competency. The fourth-year students, who have adapted to the basic clinical environment through their training in the third year, are prospective nurses who have to perform patient care in teams with specialists and assistants from various hospitals. Such tasks require basic knowledge of teamwork and communication. Therefore, in Integrated Nursing Practice III and IV, which are fourth-year practical courses, teamwork and communication were reviewed through a two-hour special lecture before clinical training. Lastly, Leadership Development, a fourth-year practical course, is the capstone course of the university. Therefore, all topics on patient safety, except IPSG, were reviewed through this course to ensure that students are equipped as nurses before their clinical training (Table 1).

\section{Linkage between patient safety topics and theoretical and practical courses}

To assess the linkage of patient safety-related education according to the program outcomes of the curriculum, performance criteria for required and elective major courses were presented according to the performance criteria set by the program outcomes. For instance, among the two performance criteria of patient safety and quality improvement, six core courses and an elective course were linked to the performance criterion of "students can explain the principles of patient safety and quality improvement." These are Understanding of Nursing, Introduction to Clinical Nursing Practice I, Introduction to Clinical Nursing Practice II, Communication II, Integrated Nursing Practice I/ II, Nursing Management, and Patient Safety (elective). Additionally, five core courses were linked to the performance criterion of "students can perform nursing practice according to guidelines and procedures for improving patient safety and quality:" Communication II, Integrated Nursing Practice I/ II, Integrated Nursing Practice III/IV, Leadership Development, and Clinical Reasoning. The course on Clinical Reasoning was designed to assess the achievement of all expected program outcomes at the end of the four-year nursing program; further development of courses to integrate the assessment of patient safety competence into current course outcomes is required but is not within the scope of this study.

Throughout the curriculum, patient safety and quality improvement were achieved through one course in the first year, two courses in the second year, two courses in the third year, and four courses in the fourth year. The integrated curriculum was designed to achieve the performance criteria according to the learning outcomes of patient safety and quality improvement programs through 10 courses consisting of required and elective major courses. For major courses, learning outcomes were measured through the evaluation of performance criteria. 
Table 1 Linkage between topics of patient safety and required major courses

\begin{tabular}{|c|c|c|c|c|c|c|c|c|c|}
\hline \multirow[t]{2}{*}{ Course } & \multirow[b]{2}{*}{ Year } & \multirow[b]{2}{*}{ Title } & \multirow[b]{2}{*}{ Outline } & \multicolumn{6}{|c|}{$\begin{array}{l}\text { Learning Hours by } \\
\text { Patient Safety Topics }\end{array}$} \\
\hline & & & & A & B & $C$ & $D$ & E & $\mathrm{F}$ \\
\hline \multirow[t]{4}{*}{ Theoretical } & 1 & $\begin{array}{l}\text { Understanding of } \\
\text { Nursing }\end{array}$ & $\begin{array}{l}\text { A course offered in the first semester of the first year. It provides } \\
\text { opportunities to learn the main concepts of nursing, history of nursing, and } \\
\text { the range of tasks and professional values of nursing. Moreover, it helps } \\
\text { students to prepare for their own role as professional nurses through an } \\
\text { understanding of the nursing discipline. }\end{array}$ & 2 & & & 1 & & \\
\hline & 2 & $\begin{array}{l}\text { Introduction to } \\
\text { Clinical Nursing } \\
\text { Practice } 1 / / 1\end{array}$ & $\begin{array}{l}\text { This course aims to provide knowledge and skills in basic nursing techniques, } \\
\text { including core basic nursing techniques for patients to second-year nursing } \\
\text { students who are soon to perform their first clinical practice. Students who } \\
\text { have completed this course can apply their knowledge and solve various } \\
\text { health problems in patients. }\end{array}$ & 1 & & & & & 1 \\
\hline & 3 & Communication II & $\begin{array}{l}\text { This course aims to improve therapeutic communications skills with various } \\
\text { patients in clinical settings where nurses are active and improve } \\
\text { communication skills within groups and organizations to facilitate } \\
\text { cooperation between professionals. }\end{array}$ & & 1 & $1^{*}$ & & & \\
\hline & 4 & Nursing Management & $\begin{array}{l}\text { This course explains the function of planning, organization, human resource } \\
\text { management, command, and control such that the role of a nursing } \\
\text { manager can be efficiently performed in a diversified social and health- } \\
\text { related environment. This course helps individuals to solve problems in nurs- } \\
\text { ing management, understand the characteristics of nursing, and play a pro- } \\
\text { fessional role as a nurse for advocating patient rights. }\end{array}$ & & & & & 6 & \\
\hline \multirow[t]{3}{*}{ Practical } & 3 & $\begin{array}{l}\text { Integrated Nursing } \\
\text { Practice I/II }\end{array}$ & $\begin{array}{l}\text { This course allows to identify factors related to nutrition-metabolism- } \\
\text { elimination, activity-rest, cognition-perception, self-concept-value/belief, roles/ } \\
\text { relationships-stress/coping, and sexuality-reproduction function of patients in } \\
\text { the development cycle from birth to death in addition to health problems } \\
\text { resulting from these factors. This course helps nursing students select the ap- } \\
\text { propriate procedures to solve such health problems. }\end{array}$ & $0.5^{*}$ & & & $0.5^{*}$ & & $0.5^{*}$ \\
\hline & 4 & $\begin{array}{l}\text { Integrated Nursing } \\
\text { Practice III/IV }\end{array}$ & $\begin{array}{l}\text { This course allows to identify problems that hinder the health function of } \\
\text { individuals, families, and communities with complex and special health } \\
\text { problems over the life cycle and solve health problems through critical } \\
\text { thinking. This course also induces primary health management and health } \\
\text { promotion based on the health needs of individuals, families, and local } \\
\text { communities and foster nursing leadership in nursing students so that they } \\
\text { can actively respond to changes with organizational management capacities. }\end{array}$ & & $1^{*}$ & $1^{*}$ & & & \\
\hline & 4 & $\begin{array}{l}\text { Leadership } \\
\text { Development }\end{array}$ & $\begin{array}{l}\text { This study aims to prepare fourth-year students for leadership and profes- } \\
\text { sional roles and help them successfully transition from students to profes- } \\
\text { sional nurses. Moreover, this course helps students understand the scope and } \\
\text { role of nursing in hospital settings, the leadership required according to vari- } \\
\text { ous situations, the importance of competencies (ethical and critical decision } \\
\text { making, co-operation with other professionals, communication, and establish- } \\
\text { ment of work relations). Students also have opportunities to evaluate their } \\
\text { leadership competencies through practical application, and the course offers } \\
\text { desirable leadership education required to be a professional nurse. }\end{array}$ & $1^{*}$ & ${ }^{*}+$ & $*$ & * & $1^{*}$ & * \\
\hline
\end{tabular}

A: Patient safety principles; B: Teamwork; C: Communication; D: Patient engagement; E: Risk management \& Quality improvement; F: IPSG standard

* Courses where academic achievement are evaluated

† If time is not indicated, these topics were included during the practical sessions without separate lecture

In addition, patient safety topics suitable for the Korean health care environment were set at the level of nursing colleges to increase their utilization. The systemically linked curriculum was integrated through continuous feedback and meetings of the authors. These included a JCI consultant, who is an expert in patient safety (A), and the curriculum committee members (B, C, D, E, F, G, H, $\mathrm{Y}$, and $\mathrm{J}$ ), and an advisory committee with three experts in health care professional education. Topics on patient safety were distributed across the appropriate level each year, and these were integrated into the curriculum by linking the theoretical and practical courses.

\section{Development of PSC self- assessment checklist for} students

A PSC checklist was developed as patient safety competencies can be integrated and experienced in clinical practice based on knowledge and attitudes acquired through the theoretical courses. The PSC checklist was designed to be used as a tool for students to acquire patient safety competencies in clinical settings naturally. The list of observation or performance items and their achievement can be the criteria for course outcome evaluation. (e.g., Students mark the PSC checklist items they observed or 
performed on a checklist during each practice setting and submit it at the end of the course.).

This included 47 specific patient safety items that can be applied in clinical practice, primarily derived through a literature review and consultation with patient safety experts. Content validity tests for clinical instructors on the derived items showed a scale content validity index (CVI) of .91. A total of six items, including four items with an item CVI of less than .75(a. a. write an accident/ incident report, b. administer high-risk drugs according to hospital policy, c. write a report on any identified risks to patient safety, $d$. find out the number of falls in the ward) and two items with a corrected item to a total correlation value of less than .3 (a. accompany the newly admitted patient to understand the patient's experience, b. fill out the checklist that the nurse uses), were excluded (In the case of items that can be replaced by role-playing, most of the respondents responded without considering the possibility of role play, so even if the score was low, it was not excluded) (see Additional file 1). Similar items were compounded of the remaining 41 items, and the authors' consensus retained the 24 items. Each item was linked to the three performance methods (observation, conduct, and discussion) to create a checklist. Afterward, the performance methods for the 24 items of the checklist were changed to two methodsobservation and conduct-in the faculty workshops.

The items went through a review process by one patient safety expert and one professor with expertise in patient safety. In this process, the "Find out how many steps are in the IV pump set up procedure" item among the 24 items was deleted to reflect the expert opinion that it is ineffective for students to learn the human factor. Therefore, the final 23 PSC checklist items were derived. Subsequently, the subject and verb of the sentences were organized consistently to help the students clearly understand the items to be observed and conducted. The contents of the PSC Checklist were reviewed and agreed upon through a curriculum workshop. Further, the final draft of the checklist was prepared through an interview with a with a $\mathrm{PhD}$ student in the the Korean language (Table 2). Table 3 presents the main suggestions and strategies for integrating the patient safety component into the existing curriculum.

\section{Discussion}

Our study identified the patient safety competency topics suitable in the Korean educational context and presented a practical case of curriculum reform incorporating these topics in the existing curriculum. The integrated patient safety curriculum consisted of six topics based on the context and environment of the curriculum that students experience for 4 years. Integrating patient safety topics into the curriculum was demonstrated, and the teaching methods within the curriculum system were suggested by presenting topics according to specific courses to the educators. Patient safety education in the undergraduate nursing curriculum was revealed to be not systematically linked within or indicated in the official curriculum [22]. To our knowledge, this is the first study to design an integrated curriculum for nursing students to achieve patient safety competencies, and the results are significant as this study provided the basis for the development of a curriculum for enhancing patient safety competencies in nursing students.

Reaching a consensus with nursing education instructors on establishing and integrating necessary patient safety topics into the curriculum is fundamental [23]. This study is significant as every professor participating in the curriculum development recognized the importance of patient safety education and integrated the topics into the existing curriculum to reach a consensus. Moreover, this study did not design a separate curriculum by limiting patient safety topics to one independent course or practical setting. Instead based on the principles of continuity and sequence of the principles of curriculum organization by Tyler [24], this study attempted to continuously provide deep and broad learning and systematically distribute patient safety topics sequentially across the curriculum. Silva et al. analyzed 13 studies through an integrative review of patient safety education methods and contents, reporting that only a few elements related to patient safety were included in the curriculums. Further, most topics were sporadically taught without linking them with the other topics [22]. There are debates about the advantages and disadvantages of a single course on patient safety competencies and integration of patient safety factors across the curriculum. However, it has been argued that every topic of patient safety needs to be dealt with in-depth throughout the curriculum for health care professionals rather than adopting a superficial approach, especially in courses that link theory and practice [25]. Therefore, instructors should first recognize and sympathize with the significance of applying patient safety competencies to the curriculum to reflect patient safety competencies in the curriculum to reform it.

Learning is mostly done in classrooms and laboratories; however, the effects of learning are seen in clinical training. Significantly, the contents and teaching methods for patient safety education vary greatly between schools [26]. Furthermore, a better understanding of patient safety and developing educational methods to facilitate this understanding must come first in undergraduate nursing education so that nursing students can perform their role as prospective nurses during clinical training [27]. Therefore, this study developed a patient 
Table 2 Patient safety competency checklist (PSC Checklist) for clinical practicum

\begin{tabular}{|c|c|c|c|c|c|}
\hline \multirow[t]{2}{*}{ Course } & \multirow[t]{2}{*}{ Learning content } & & \multirow[t]{2}{*}{ Item } & \multicolumn{2}{|l|}{ Performance } \\
\hline & & & & Observation & Conduct \\
\hline \multirow[t]{14}{*}{$\begin{array}{l}\text { Integrated } \\
\text { Nursing } \\
\text { Practice I/II }\end{array}$} & $\begin{array}{l}\text { 1. Patient safety } \\
\text { principles }\end{array}$ & $\begin{array}{l}\text { 1) Concept } \\
\text { of patient } \\
\text { safety }\end{array}$ & $\begin{array}{l}\text { 1. The doctor must check the patient identification before treatment, and, } \\
\text { if the doctor does not, the nurse should check the patient identification }\end{array}$ & $\mathrm{V}$ & \\
\hline & & 2) System & $\begin{array}{l}\text { 2. Analyze the cause of errors or near miss (events that were discovered } \\
\text { before the accident and did not harm the patient) }\end{array}$ & & V \\
\hline & & $\begin{array}{l}\text { 3) Human } \\
\text { factor }\end{array}$ & $\begin{array}{l}\text { 3. Check how often nurses stop and perform other tasks during the } \\
\text { administration of medication and assess the cause }\end{array}$ & & V \\
\hline & $\begin{array}{l}\text { 4. Patient } \\
\text { Engagement }\end{array}$ & & $\begin{array}{l}\text { 4. Medical staffs (clinicians and nurses) actively share information with } \\
\text { patients and guardians during rounds }\end{array}$ & V & \\
\hline & & & $\begin{array}{l}\text { 5. Make eye-level contact with the patients and introduce myself to the pa- } \\
\text { tients before starting given tasks }\end{array}$ & & V \\
\hline & & & $\begin{array}{l}\text { 6. Check whether the patient participated in discharge education and } \\
\text { understood the contents of the education }\end{array}$ & & V \\
\hline & & & 7. Encourage patients to participate in education for fall prevention & & V \\
\hline & 6. IPSG & & $\begin{array}{l}\text { 8. Accurately identify the patient (e.g., measuring vital signs, measuring liver } \\
\text { blood glucose, administrating medication, collecting samples, treating the } \\
\text { patient, and providing prescribed diet) }\end{array}$ & & V \\
\hline & & & 9. Make a list of high-risk drugs and other drugs that look and sound similar & & V \\
\hline & & & $\begin{array}{l}\text { 10. Store high-risk medications in special locations where it is specified, } \\
\text { locked, or designated }\end{array}$ & V & \\
\hline & & & 11. Comply with cautionary measures when high-risk drugs are administered & V & \\
\hline & & & $\begin{array}{l}\text { 12. When a patient arrives at the operating room, be aware of the pre- } \\
\text { operative confirmation procedures and participate in sign-in/time-out/sign- } \\
\text { out }^{\mathrm{a}} \text {. }\end{array}$ & V & \\
\hline & & & 13. Monitor the hand hygiene practices of the medical staff in the ward & & V \\
\hline & & & 14. Fill-out fall risk assessment sheet of patients & & V \\
\hline \multirow{5}{*}{$\begin{array}{l}\text { Integrated } \\
\text { Nursing } \\
\text { Practice III/IV }\end{array}$} & 2. Teamwork & & 15. Assess how many medical staff are involved in the care of one patient & & V \\
\hline & & & 16. Participate in the medical staff rounds (doctors and nurses) & $\vee$ & \\
\hline & 3. Communication & & $\begin{array}{l}\text { 17. Comply with principles and procedures of oral prescription when verbal } \\
\text { prescriptions are given over the phone }\end{array}$ & V & \\
\hline & & & $\begin{array}{l}\text { 18. Review the clinical results of patients and judge if it is urgent to contact } \\
\text { a doctor }\end{array}$ & & V \\
\hline & & & 19. Report the condition of the patients to the doctors ${ }^{b}$ & & V \\
\hline \multirow[t]{4}{*}{$\begin{array}{l}\text { Leadership } \\
\text { Development }\end{array}$} & 3. Communication & & $\begin{array}{l}\text { 20. Communicate with doctors in accordance with SBAR (situation, } \\
\text { background, assessment, recommendation) when transferring a patient (e.g., } \\
\text { rehabilitation, x-ray examination, transfer to another ward) }\end{array}$ & V & \\
\hline & $\begin{array}{l}\text { 5. Risk management } \\
\text { \& Quality } \\
\text { improvement }\end{array}$ & $\begin{array}{l}\text { 1) Risk } \\
\text { management }\end{array}$ & $\begin{array}{l}\text { 21. Identify factors in the ward that may harm patient safety (e.g., } \\
\text { contaminated laundry without covers in the hallway, filled syringe needles, } \\
\text { similar-looking drugs stored close to each other in one place, slippery floors, } \\
\text { unlabeled syringes) }\end{array}$ & & V \\
\hline & & $\begin{array}{l}\text { 2) Quality } \\
\text { improvement }\end{array}$ & $\begin{array}{l}\text { 22. Be aware of the activities (e.g., monitoring of events, analysis of patient } \\
\text { complaints, and checking red signal events) and methods (e.g., clinical } \\
\text { practice improvement, root cause analysis, failure mode and effect analysis, } \\
\text { flow charts, cause and effect diagrams, Pareto chart) performed in the ward } \\
\text { to improve the quality of the ward }\end{array}$ & & V \\
\hline & & & $\begin{array}{l}\text { 23. Plan strategies to improve the problems and check whether the } \\
\text { improvement is based on evidence (e.g., literature, clinical guidelines, data) }\end{array}$ & & V \\
\hline
\end{tabular}

\footnotetext{
${ }^{a}$ Applicable only to students of operating room practice, not applicable to students who do not have operating room training

${ }^{b}$ Items that can be replaced by role play
}

safety checklist to evaluate the role of nurses in the frequently encountered patient safety situations during clinical practice. Learning patient safety and acquiring practical skills and perspectives of patient-centered treatment, starting as early as in undergraduate courses, would help nursing students adapt to clinical training.

To successfully integrate patient safety into the nursing curriculum, nursing faculty should be well-prepared 
Table 3 Summarizing the main suggestions and strategies for integrating curriculum

\section{Steps}

1) Literature review

2) Analysis of course syllabus

3) Selection of courses related to patient safety topics

\section{4) Development of} evaluation tool

\section{Main suggestions}

Confirmation of educational content consistent with the position of a credible institution (e.g., WHO, CASN and JCl)

Patient safety topics decision reflecting the characteristics of each university's curriculum and practice environment

Analyzing all courses offered from the first to fourth year of the program

Selection of subjects according to students' level of understanding and patient safety topics topics by courses

Providing the special lecture before starting clinical practice course

The linkage between patient safety topics and theoretical and practical courses

Patient safety competency evaluation through PSC checklist

\section{Strategies for integrating curriculum}

- For example, WHO's "what is patient safety" and CASN's "contribute to a culture of patient safety" were derived as "concept of patient safety," one of the sub-topics of patient safety principles, the patient safety topic of this university. By integrating WHO's "Why applying human factors is important for patient safety?" and CASN's "Optimize human and environmental factors," the topics were derived as "Human factor" and "Systems" among the subtopics of patient safety principles.

- In the case of this university, a clinical practice course is provided from the third year (for one year) at a JCl-certified medical institution. Thus, IPSG, which can be repeatedly learned in various settings according to the curriculum's principle of continuity and integration, has been added as the educational content.

- The syllabus of the existing curriculum needs to be analyzed to assess how patient safety factors were reflected in the existing curriculum and the courses in which they needed to be reflected.

- The assignment of patient safety topics within these courses was considered the level of students (e.g., The basic concepts of patient safety and patient engagement were introduced in Understanding of Nursing, which is the first major course offered in the first year of the program.)

- It is necessary to reach a scholarly consensus throughout the school through several faculty meetings.

(e.g., In this university, teamwork was included in the Nursing Management course, but after the faculty meeting, agreed that communication the most important capability in teamwork.

Therefore, it was decided to add communication content related to teamwork to the Communication theory II course)

- The special lecture is provided to third-year students who are new to clinical practicum before they experience the field is to remind them about patient safety topics to enhance the integration of theory-practice and safety accident prevention and coping competency.

- To assess the linkage of patient safety-related education according to the program outcomes of the curriculum, performance criteria for required and elective major courses need to be presented according to the performance criteria set by the program outcomes.

- The PSC checklist is designed to be used as a tool to induce students to naturally acquire patient safety topics in the clinical environment by using them during the clinical practicum courses. Therefore, the number of performances and the achievement of the items can be the criteria for a part of the evaluation(e.g., Students mark the PSC checklist items they observed or performed on a checklist during each practice course and submit it at the end of the course.) and familiar with teaching modern patient safety concepts systematically. Notably, instructors who lack competence in patient safety education have been continuously criticized as hindering patient safety education [13]. The lack of patient safety competency in nursing education and among clinical professionals is reported to result from a lack of understanding on how to educate students on patient safety and incorporate patient safety principles in academic and clinical settings [28]. Although the role of nursing faculty is important for improving patient safety outcomes, previous studies have mostly focused on students [23]. Some studies have evaluated the patient safety competency of nursing faculty [29]. However, no studies have assessed the relationship with the educational outcomes of teachers through the development of educational programs to enhance patient safety competencies in nursing faculty. In particular, the Nurse Educator Core Competencies, developed by the WHO in 2016, presented "curriculum and implementation" as the second among eight core competencies of nursing educators. Thereby encouraging nursing educators to develop skills to design, implement, and monitor curriculums based on the latest educational models, principles, and appropriate evidence [30]. Thus, specific curriculums to enhance the understanding of the educational content of patient safety and 
appropriate teaching methods need to be developed, and continuous faculty development programs for applying such curriculums need to be provided. As the role of nursing faculty is important in improving patient safety outcomes in students, future studies that examine the influence of faculty competency in patient safety on student outcomes are recommended.

This study presented patient safety topics and methods applicable to universities by developing an integrated patient safety curriculum. However, each university has different curriculums, credit systems, and courses. Thus, revisions to the curriculum developed in this study will be necessary, and the PSC Checklist will also need to be modified to reflect differences in clinical training. Moreover, the needs of students and clinical practice education officials were not surveyed, and the opinions of the stakeholders who underwent the curriculum could not be reflected. These limitations need to be compensated for through a pilot study using the checklist. This is a methodological study that proposed a process for integrating patient safety into the existing curriculum. As the developed curriculum could not be applied to nursing students, a follow-up study to apply and evaluate the integrated patient safety curriculum is suggested.

\section{Conclusion}

This study established patient safety topics suitable for nursing education in Korea and integrated them into the existing curriculum. The key topics include basic principles, teamwork, communication, patient engagement, risk management and quality improvement, and IPSG. These are required for patient safety in nursing students and were presented, and this study proposed developing a systematically integrated curriculum for nursing faculty. This study demonstrated that patient safety topics should be dealt with in both theoretical and practical settings across the entire nursing curriculum per the continuity and sequence of education principles. Moreover, the linkage between theory and practice was secured by creating a checklist that students can use in clinical settings. The process of reforming the curriculum has provided an opportunity to recognize the importance of including nursing faculty, students, and clinical instructors related to patient safety education in improving the quality of health care through patient safety. This study provided a foundation for integrating the curriculum of patient safety nursing education in Korea's early stages. It is thought to help develop patient safety competency and ultimately improve patient safety performance by facilitating the clinical adaptation of new nurses.

\section{Abbreviations}

CASN: Canadian Association of Schools of Nursing; CVI: Content validity index; IPSG: International Patient Safety Goals; PSC Checklist: Patient safety competency checklist; QSEN: Quality and Safety Education for Nurses

\section{Supplementary Information}

The online version contains supplementary material available at https://doi. org/10.1186/s12912-021-00694-0.

\section{Additional file 1.}

\section{Acknowledgments}

Not applicable.

\section{Authors' contributions}

Conceptualization: HKL, TWL, MNC, HJL, SHK, HKD; methodology: YJJ, HKL, TWL, MNC, HJL, SHK; validation: SAK, SHC, JOP; data curation: YJJ, SYP; investigation: YJJ, SYP; formal analysis: YJJ, HKL, HKD, YMK, SYP; supervision: HKL; project administration: HKL, SYP; funding acquisition: HKL, TWL, MNC, HJL, SHK; visualization: YJJ, YMK, SYP; writing —original draft: YJJ, HKL, YMK, SYP; Writing - review and editing: HKL, YJJ, MNC, HJL, SHK, HKD, SAK, SHC, JOP, YML, SYP. All authors read and approved the final manuscript.

\section{Funding}

This research was supported by a grant of Curriculum Reform in Baccalaureate Nursing Education (6-2019-0048) of Yonsei University College of Nursing.

Availability of data and materials

All data supporting the findings of this study are available from the corresponding author on request.

\section{Declarations}

Ethics approval and consent to participate Not applicable.

\section{Consent for publication}

Not applicable.

\section{Competing interests}

The authors declare that they have no competing interests.

\section{Author details}

${ }^{1}$ Mo-Im Kim Nursing Research Institute, College of Nursing, Yonsei University, Seoul, Republic of Korea. ${ }^{2}$ Joint Commission International, Illinois, United States. ${ }^{3}$ College of Nursing, Research Institute of Nursing Science, Jeonbuk National University, Jeonju, Republic of Korea.

Received: 26 April 2021 Accepted: 28 August 2021

Published online: 17 September 2021

\section{References}

1. Agency for Healthcare Research and Quality. AHRQ Quality Indicators: Guide to Patient Safety Indicators. Rockville: Agency for Healthcare Research and Quality (US); 2003.

2. Donaldson MS, Corrigan JM, Kohn LT. To err is human: building a safer health system; 2000

3. Suliman M. Measuring patient safety competence among nursing students in the classroom and clinical settings. Nurs Educ Perspect. 2019;40(3):E3-7. https://doi.org/10.1097/01.NEP.0000000000000460.

4. McFadden KL, Stock GN, Gowen CR III. Leadership, safety climate, and continuous quality improvement: impact on process quality and patient safety. Health Care Manag Rev. 2015;40(1):24-34. https:/doi.org/10.1097/ HMR.0000000000000006.

5. Yum HK. Management and perspectives of patient safety in healthcare. J Korean Med Assoc. 2013;1, 56(6, 6). https://doi.org/10.5124/jkma.2013.56.6.4 54.

6. Cohen $\mathrm{H}$, Tuohy N, Carroll R. The risk management professional and medication safety. J Healthcare Risk Manag. 2009;29(1):34-43. https://doi. org/10.1002/jhrm.20004.

7. Hughes R, editor. Patient safety and quality: An evidence-based handbook for nurses;2008.

8. Ministry of Health and Welfare of Korea. The first comprehensive plan for patient safety, 2018-2022. [cited 2021 JAN 6] Available from http://www. 
mohw.go.kr/react/jb/sjb030301vw.jsp?PAR_MENU_ID=03\&MENU_ID=031 9\&CONT_SEQ=344873\&page $=1$.

9. Stevens DP. Finding safety in medical education; 2002.

10. Sandars J, Bax N, Mayer D, Wass VA, Vickers R. Educating undergraduate medical students about patient safety: priority areas for curriculum development. Med Teach. 2007;29(1):60-1. https://doi.org/10.1080/01421 590601087546.

11. Ladden MD, Bednash G, Stevens DP, Moore GT. Educating interprofessional learners for quality, safety and systems improvement. J Interprof Care. 2006; 20(5):497-505. https://doi.org/10.1080/13561820600935543.

12. Cronenwett L, Sherwood G, Barnsteiner J, Disch J, Johnson J, Mitchell P, et al. Quality and safety education for nurses. Nurs Outlook. 2007;55(3):12231. https://doi.org/10.1016/.joutlook.2007.02.006.

13. Safety WP, World Health Organization. Patient safety curriculum guide: multi-professional edition; 2011

14. Altmiller G, Hopkins-Pepe L. Why quality and Safety education for nurses (QSEN) matters in practice. J Contin Educ Nurs. 2019;50(5):199-200. https:// doi.org/10.3928/00220124-20190416-04.

15. Canadian Association of Schools of Nursing and Canadian Patient Safety Institute. Learning Outcomes for Patient Safety in Undergraduate Nursing Curricula. Ottawa; 2018.

16. British Columbia Nurses' Union. 2015. Position statement: Nursing workload and patient safety. [cited 2021 JAN 22] Available from https://www.bcnu. org/AboutBcnu/Documents/position-statement-patient-safety.pdf

17. Masters K. Integrating quality and safety education into clinical nursing education through a dedicated education unit. Nurse Educ Pract. 2016;17: 153-60. https://doi.org/10.1016/j.nepr.2015.12.002.

18. Kim YM, Yoon YS, Hong HC, Min A. Effects of a patient safety course using a flipped classroom approach among undergraduate nursing students: a quasi-experimental study. Nurse Educ Today. 2019;79:180-7. https:/doi. org/10.1016/j.nedt.2019.05.033

19. Balachandran S, Venkatesaperumal R, Dsouza M. Teaching patient Safety in undergraduate nursing education. Int J Health Sci Res. 2017:375-81.

20. Gordon M. Nursing diagnosis: process and application. 3rd ed. St. Louis: Mosby; 1994

21. Joint Commission International. International Patient Safety Goals 2020. [cited MAY 15, 2020] Available from http://www.jointcommissioninterna tional. org/improve/international-patient-safety-goals/.

22. Silva AM, Bim LL, Bim FL, Sousa AF, Domingues PC, Nicolussi AC, et al. Patient safety and infection control: bases for curricular integration. Rev Bras Enferm. 2018;71(3):1170-7. https://doi.org/10.1590/0034-7167-2017-0314.

23. Mansour MJ, Al Shadafan SF, Abu-Sneineh FT, AlAmer MM. Integrating patient safety education in the undergraduate nursing curriculum: a discussion paper. Open Nurs J. 2018;12:125.

24. Tyler RW. Basic principles of curriculum and instruction: University of Chicago press; 2013. https://doi.org/10.7208/chicago/9780226086644.001. 0001.

25. de Sousa ÁF, Matos MC, de Matos JG, Sousa LR, Moura ME, de Andrade D. Prevention and control of infection in professional nursing training: a descriptive study. Online Brazilian J Nurs. 2017;16(2):199-208. https://doi. org/10.17665/1676-4285.20175560.

26. Lee NJ, Jang H, Park SY. Patient safety education and baccalaureate nursing students' patient safety competency: a cross-sectional study. Nurs Health Sci. 2016;18(2):163-71. https://doi.org/10.1111/nhs.12237.

27. Usher K, Woods C, Conway J, Lea J, Parker V, Barrett F, et al. Patient safety content and delivery in pre-registration nursing curricula: a national crosssectional survey study. Nurse Educ Today. 2018;66:82-9. https://doi.org/10.1 016/j.nedt.2018.04.013.

28. Jang $\mathrm{H}$, Lee NJ. Patient safety competency and educational needs of nursing educators in South Korea. PLoS One. 2017;12(9):e0183536. https:// doi.org/10.1371/journal.pone.0183536.

29. Ahn S, Lee NJ, Jang H. Patient Safety Teaching Competency of Nursing Faculty. J Korean Acad Nurs. 2018;48(6):720-30. https://doi.org/10.4040/jka n.2018.48.6.720.

30. World Health Organization. Nurse educator core competencies; 2016.

\section{Publisher's Note}

Springer Nature remains neutral with regard to jurisdictional claims in published maps and institutional affiliations.

\section{Ready to submit your research? Choose BMC and benefit from}

- fast, convenient online submission

- thorough peer review by experienced researchers in your field

- rapid publication on acceptance

- support for research data, including large and complex data types

- gold Open Access which fosters wider collaboration and increased citations

- maximum visibility for your research: over $100 \mathrm{M}$ website views per year

At BMC, research is always in progress.

Learn more biomedcentral.com/submissions 